\title{
A FORMAÇÃO CONTINUADA DE PROFESSORES E PEDAGOGOS DO ENSINO MÉDIO: PRIMEIROS RESULTADOS DA FORMAÇÃO NO ÂMBITO DO PACTO NACIONAL PELO FORTALECIMENTO DO ENSINO MÉDIO
}

\author{
Sandra Regina de Oliveira Garcia - UEL \\ sandragarciapr@hotmail.com \\ Maria das Graças Ferreira - UEL \\ mgrafer59@gmaiL.com
}

O Programa Pacto Nacional pelo Fortalecimento do Ensino Médio - Formação continuada de professores e equipes pedagógicas - é uma ação coordenada pelo Ministério da Educação em todas as unidades da Federação, com a participação das instituições de ensino superior públicas e as secretarias de estado de educação. No Paraná a UEL é responsável pela formação dos professores e equipes pedagógicas, dos formadores regionais e orientadores de estudo vinculados aos núcleos regionais de educação de Londrina, Apucarana e Ivaiporã. O programa privilegia a articulação entre teoria e prática no processo de formação docente e considera a escola como lócus de formação continuada. Propõe a reconstrução coletiva do projeto político-pedagógico, tendo como fio condutor os sujeitos do ensino médio e a formação humana integral. Em termos metodológicos, o projeto compreende o professor como um sujeito epistêmico, que elabora e produz conhecimentos com base na compreensão da realidade e nas possibilidades de transformação da sociedade. Este texto apresenta os resultados do projeto, coletado por meio de questionários que foram respondidos por todos os professores participantes. Os resultados preliminares apontam o quão importante e necessário é a formação do professor do Ensino Médio, mas também apontam as fragilidades deste processo.

Palavras-chave: Política Educacional, Ensino Médio, Formação continuada.

\section{INTRODUÇÃO}

A Formação de professores no âmbito do Pacto Nacional de Fortalecimento do Ensino Médio - PNEM sob responsabilidade da UEL atendeu três NREs do norte do Paraná, Londrina, Apucarana e Ivaiporã, envolvendo 49 municípios, 169 escolas, 174 grupos formados, 174 Orientadores de Estudo e 2030 professores cursistas.

Os grupos de estudo foram constituídos no interior de cada escola, sendo que, as atividades individuais ocorreram na hora-atividade de cada professor durante a semana e os encontros coletivos aos sábados, decisão tomada pela SEED/PR, facultado aos grupos a possibilidade dos encontros ocorrerem durante a semana, mas a maioria só conseguiu organizar as atividades aos sábados.

A formação do formadores ocorreu quinzenalmente na Universidade, sendo que, a formação do Orientadores, que no projeto original do MEC, seria realizada pelos formadores regionais ocorreu mensalmente na Universidade, o que através das avaliações realizadas demonstrou ter sido uma decisão acertada, pois possibilitou um diálogo com as questões presentes no chão da escola. 
O Pacto Nacional pelo Fortalecimento do Ensino Médio - PNEM foi elaborado pelo Ministério da Educação como um conjunto de ações articuladas com o objetivo de elevar a qualidade do Ensino Médio brasileiro, em suas diferentes modalidades. O Pacto como é denominado representa a articulação e a coordenação de ações e estratégias entra a União e os governos estaduais e distrital para a formulação de políticas para o Ensino médio.

Uma das ações propostas no âmbito do PNEM foi o Programa de Formação continuada de professores e equipes pedagógicas do Ensino Médio da Rede Estadual de Educação com o objetivo de promover a formação continuada dos professores e coordenadores pedagógicos que atuam no ensino médio público e rediscutir e atualizar as práticas docentes em conformidade com as Diretrizes Curriculares Nacionais do Ensino Médio - DCNEM, com o diferencial que deveria ocorrer no chão da escola, possibilitando que todos os professores pudessem participar através de adesão dos mesmos.

É um programa com amplitude nacional, operacionalizado pelas instituições de ensino superior públicas federais e estaduais. As Instituições de Ensino Superior são responsáveis pela formação dos formadores regionais, os orientadores de estudo e professores em articulação com as Secretarias de Estado de Educação - SEDUCs. As SEDUCs são responsáveis em disponibilizar os formadores regionais para 0 acompanhamento da formação dos orientadores de estudo e dos professores e coordenadores pedagógicos nas escolas. Os orientadores de estudo são responsáveis pela coordenação do trabalho nas escolas junto aos professores e coordenadores pedagógicos do Ensino Médio. (MINISTÉRIO DA EDUCAÇÃO, 2014)

O processo formativo tem como eixo a temática "Sujeitos do Ensino Médio e formação Humana Integral", que orientará a discussão e o trabalho em todas as etapas do curso.

A metodologia de trabalho do processo de formação é desenvolvida de maneira articulada e integrada com as Universidades, Secretarias Estaduais e Escolas. Tem o professor como o principal sujeito do processo formativo compreendido como "[...] um sujeito epistêmico, que elabora e produz conhecimentos com base na compreensão da realidade e nas possibilidades de transformação da sociedade" (MINISTÉRIO DA EDUCAÇÃO, 2014, p05).

As atividades do curso foram organizadas em dois momentos distintos. $\mathrm{O}$ primeiro momento foi composto por atividades individuais do professor que deveria organizar seu próprio tempo institucional para a leitura dos textos básicos do curso e deveria registrar as reflexões realizadas durante suas leituras nas discussões com o grupo na escola. Além disso deveria realizar pelo menos uma das atividades propostas no material de estudo no contexto de sala de aula. Todo o processo foi orientado e acompanhando pelo orientador de estudo. O segundo momento foi composto por atividades coletivas.

O grupo realizou o estudo das DCNEM, dos textos sobre os campos temáticos e dos textos sobre áreas de conhecimento e seus componentes curriculares. Coube aos orientadores de estudo organizar em cada escola de Ensino Médio a proposta de formação, de acordo com a organização do trabalho pedagógico da escola adequando-o a realidade da escola. (MINISTÉRIO DA EDUCAÇÃ̃O, 2014).

$\mathrm{O}$ curso foi destinado para o professor em atividade em sala de aula e ao Coordenador Pedagógico em efetivo exercício em 2014 que atuavam no Ensino Médio 


\section{SEMINÁRIO DE PESQUISA EM CIÊNCIAS HUMANAS - SEPECH \\ Humanidades, Estado e desafios didático-científicos \\ Londrina, 27 a 29 de julho de 2016}

Ensino, Médio Integrado, Normal/Magistério, das modalidades de Educação de Jovens e Adultos, Especial, do Campo, Indígena, Quilombola e de pessoas em regime de acolhimento ou internação e em regime de privação de liberdade.

$\mathrm{O}$ curso foi desenvolvido em duas etapas, tendo como fio condutor das mesmas os "Sujeitos do Ensino Médio e Formação Humana Integral", com o objetivo de compreender as Diretrizes Curriculares Nacionais do Ensino Médio e refletir coletivamente sobre a prática docente no Ensino Médio. A primeira etapa A $1^{\mathrm{a}}$ etapa compreendeu os seguintes campos temáticos: Sujeitos do Ensino Médio e formação humana integral; Ensino Médio e formação humana integral; O currículo do Ensino Médio, seus sujeitos e o desafio da formação humana integral; Organização e gestão do trabalho pedagógico; Avaliação no ensino médio; e Áreas de conhecimento e integração curricular. Todo o processo da primeira etapa completou uma carga horária de 100horas. (MINISTÉRIO DA EDUCAÇÃO, 2014).

A segunda Etapa privilegiou as Áreas de Conhecimento do Ensino Médio com o objetivo de refletir sobre as áreas de conhecimento e as relações entre elas e seus componentes curriculares contextualizadas no Projeto Político Pedagógico da escola. Considerando-se a diversidade na garantia da educação para todos, e suas articulações com os princípios e desenho curricular das DCNEM e dos Direitos à Aprendizagem e ao Desenvolvimento: Ciências Humanas (Sociologia, Filosofia, História e Geografia); Ciências da Natureza (Química, Física, Biologia); Linguagens (Língua Portuguesa, Artes, Educação Física, Língua Estrangeira Moderna); e Matemática; e a Organização do trabalho pedagógico no ensino médio. O processo também teve 100 horas de duração.

Com o objetivo de apresentar os resultados do Programa desenvolvido junto a Universidade Estadual Londrina, estruturamos o presente texto na seguinte ordem: para uma melhor compreensão da temática, analisamos, num primeiro momento, a relação entre teoria, prática e práxis docente, mostrando a imbricação existente entre essas; Em segundo discutimos a formação de professores e a difícil tarefa de relacionar teoria e prática. Em terceiro, tratamos do desenvolvimento do Pacto na Universidade Estadual de Londrina e avaliação de professores e orientadores na busca da práxis.

\section{RELAÇÃO TEORIA E PRÁTICA E A CONSTRUÇÃO DA PRÁXIS DOCENTE: DIMENSÕES}

Discutir a formação de professores na atualidade, nos coloca diante da dificuldade de pensar a formação do professor para a emancipação humana e nos provoca pensar essa emancipação no contexto das contradições geradas no contexto das grandes transformações de caráter social, político e econômico que estamos vivenciando.

A discussão sobre a formação de professores e a superação da dicotomia relação teoria e prática, visando à práxis, envolve pesquisadores das diferentes áreas do conhecimento. Para iniciar nossa reflexão buscamos em Bottomore (2001, p. 292) o conceito de práxis. Segundo o autor,

A expressão práxis refere-se, em geral a ação a atividade, e, no sentido quer lhe atribui Marx, à atividade livre, universal, criativa e auto - 


\section{SEMINÁRIO DE PESQUISA EM CIÊNCIAS HUMANAS - SEPECH \\ Humanidades, Estado e desafios didático-científicos \\ Londrina, 27 a 29 de julho de 2016}

criativa por meio do qual o homem cria (faz, produz), e transforma (conforma) seu mundo humano e histórico e a si mesmo; atividade específica ao homem, que o torna basicamente diferente de todos os outros seres. Nesse sentido o homem pode ser considerado um ser de práxis, entendida a expressão como conceito central do marxismo, e este como a 'filosofia' (ou melhor), o 'pensamento') da práxis.

A categoria práxis segundo Bottomore (2001, p. 295) vão desde o enfoque mais simplificado como atividade humana no qual o homem modifica o mundo e a si mesmo até outras mais que introduzem "noções de liberdade, criatividade, universalidade, história, futuro, revolução, etc.". práxis:

Netto; Braz (2007, p. 44) corroborando com tal reflexão destaque a categoria

permite aprender a riqueza do ser social desenvolvido: verifica-se, na e pela práxis, como, para além das suas objetivações primárias, constituídas pelo trabalho, o ser social se projeta e se realiza nas objetivações materiais e ideais da ciência, da filosofia, da arte, construindo um mundo de produtos, obras e valores - um mundo social, humano enfim, em que a espécie humana se converte inteiramente em gênero humano.

De acordo com GARCIA (2009, p.38) é preciso também expressar a compreensão da categoria práxis, da relação teoria e prática, tendo o entendimento que a práxis, segundo Vasquez (2007, p.34) é a atividade teórica e prática que transforma a natureza e a sociedade: prática, na medida em que a teoria, como guia da ação, orienta a atividade humana e teórica, na medida em que esta ação é consciente A práxis no sentido que lhe atribui Marx, não se confunde com a prática estritamente utilitária, voltada para resultados imediatos, tal como é concebido comumente. Para ele, a práxis supera essa visão imediata e ingênua, ao acentuar criticamente os condicionantes sociais, econômicos, ideológicos - históricos, que resultam da ação dos homens.

No campo educacional a categoria práxis é essencial para pensar a formação de professores. A relação teoria e a prática são componentes indissociáveis no processo de formação dos professores e a busca dessa indissociabilidade é um dilema para a construção da escola pública de qualidade.

Entretanto, esse dilema não permeia a preocupação dos professores de modo geral, pois estabelecer uma relação entre a teoria e a prática tem sido uma das tarefas mais difíceis para os professores. Isto porque as atividades do cotidiano os leva a uma rotina onde o fazer, assume uma condição tal que impossibilita o pensar por maior que seja o tempo destinado para isto. Sua ação docente acaba sendo de tal maneira repetitiva em que ele não se reconhece no seu trabalho.

As condições materiais e sociais da escola impossibilitam aos professores superar os inúmeros desafios presentes em seu cotidiano de trabalho. A perspectiva da educação como um direito e como um processo formativo contínuo e permanente, além das novas determinações com vistas a atender novas orientações educacionais, amplia as tarefas dos profissionais da educação, no que diz respeito às suas práticas. Exige-se do professor que ele seja capaz de articular os diferentes saberes escolares à prática social e ao desenvolvimento de competências para o mundo do trabalho. Em outras palavras, a 


\section{SEMINÁRIO DE PESQUISA EM CIÊNCIAS HUMANAS - SEPECH \\ Humanidades, Estado e desafios didático-científicos \\ Londrina, 27 a 29 de julho de 2016}

vida na escola e o trabalho do professor tornam-se cada vez mais complexos. Nessa perspectiva o professor não percebe a dimensão de seu trabalho, pelo contrário as objetivações dadas pelo seu trabalho não se apresentam como obra sua, pelo contrário, apresentam-se como algo que ele não se reconhece, é estranho.

Os estudos de Vazquez $(2007$, p.8) nos levam a afirmar que ““،... em qualquer esfera do conhecimento, a essência não se manifesta de maneira direta e imediata através de sua aparência e que a prática cotidiana longe de mostrá-la essa essência de modo transparente o que faz é ocultá-la". Vazquez aponta que é necessário "destruir a atitude própria à consciência comum" para que se possa atingir algo cientificamente construído pelos homens. Apenas desta forma é possível unir de forma consciente o pensamento e a ação. "Sem transcender os limites da consciência comum, não é possível uma verdadeira consciência filosófica da práxis, como também uma práxis que se eleve a um nível superior, isto é, criador" (VAZQUEZ, 2007, p.08). No entanto é necessário perceber que a "atitude natural cotidiana coexiste com a atitude filosófica surgida historicamente" (VAZQUEZ, 2007, p. 08). O autor afirma ainda que este produzir cotidianamente através das mais diversas ações, é o ponto de partida para chegar a uma "verdadeira concepção filosófica das práxis".

Exige-se do professor o desenvolvimento de ações pedagógicas que são da natureza do seu fazer, além de muitas outras práticas originadas no contexto social que extrapolam o seu trabalho pedagógico em sala de aula e exigem uma intervenção para que o processo de ensino e aprendizagem aconteça, levando-o ao processo de estranhamento de seu próprio trabalho, o que favorece a perda da centralidade da sua ação enquanto professor. Corrêa (2005) corroborando com essa reflexão salienta que aos que atuam na educação escolar, independentemente do nível de ensino e/ou modalidade de educação, são colocados vários desafios, e vem se explicitando segundo a autora uma tensão, assim discutir as contradições que permeiam tal espaço é imprescindível para a superação da velha dicotomia teoria e prática que permeia $\mathrm{o}$ trabalho docente. Corrêa (2005, p. 128) salienta que:

A compreensão da importância das relações sociais e materiais na
escola para o processo de produção da existência humana de
professores, de alunos, enfim, de todos aqueles que fazem parte de seu
coletivo, representa uma das questões de grande relevância,
especialmente, quando se busca um melhor entendimento do processo
educativo que se desenvolve na escola.

Os desafios que nos colocam ao iniciarmos uma ação, vem sempre acompanhado de apreensões em relação ao que pode acontecer no percurso de tal atividade. Com o Pacto não foi diferente até porque, os professores, sujeitos diretamente envolvidos, estão repletos de certezas e incertezas a respeito do seu cotidiano e a respeito daquilo que fazem ao longo da sua profissão. Pode-se afirmar que os professores possuem uma visão de mundo e por essa visão, interpretam o mundo principalmente a partir do trabalho que realizam rotineiramente nas escolas. 


\section{SEMINÁRIO DE PESQUISA EM CIÊNCIAS HUMANAS - SEPECH \\ Humanidades, Estado e desafios didático-científicos \\ Londrina, 27 a 29 de julho de 2016}

\section{A FORMAÇÃO DE PROFESSORES E A DIFÍCIL TAREFA DE RELACIONAR TEORIA E PRÁTICA.}

Pensar o Pacto Nacional pelo Fortalecimento do Ensino Médio é antes de tudo pensar a escola com todas as suas características; é ainda visualizar no seu interior um público especial que a busca constantemente embora muitas vezes nela não encontre o que procura. Referimo-nos aos jovens que na sua condição de cidadãos e na busca de uma formação que aponte caminhos de sucesso para suas vidas, busca na escola a resposta para as suas ansiedades e desejos. Com eles vêm também uma diversidade e variedade de sentimentos complexos o que impede ou dificulta a sua adaptação às regras impostas pela escola e que ele não compreende o seu significado. Querem uma resposta para suas necessidades e querem uma promessa de que pelo estudo poderão conquistar uma vida diferente da que tem agora e por sua vez diferente da vida que seus pais e familiares tiveram. Essa juventude é muitas vezes recebida por professores que serão responsáveis pela sua formação intelectual e humana e que não tem as respostas para as muitas perguntas que os jovens fazem, ou seja, em termos de projeção futura, as incertezas são tanto ou maior que as dos jovens. Nesse sentido, podemos afirmar que as relações entre professores e alunos na maioria das vezes se dão em meio a conflitos, desentendimentos, incompreensões, desafios, o que, em alguns casos, chega a agressão física.

Em meio a esta convivência conflituosa, como fica o aprendizado dos jovens alunos do Ensino Médio? O que conseguem aproveitar daquilo que lhes foi ensinado? Como se sentem frente aos conteúdos e avaliações? Como administram as frustrações frente a constatação de que não darão conta das inúmeras obrigações que o sistema escolar lhes impõe? O que fazer com tantos sentimentos contraditórios que os afligem? Entender o universo de manifestações que compreende a natureza do jovem estudante na atualidade, significa vê-lo na sua singularidade de sujeito ímpar, dotado de sentimentos e jeitos únicos de ver e compreender o mundo, de mostrar o seu olhar sobre o seu futuro e de se perceber parte dele, de considerar as profundas desigualdades sociais em que esse jovem está mergulhado e sofrendo as que elas lhes impõe.

Diante disso, o que a escola pode fazer por ele? E os professores, qual o papel que desempenham na sua vida presente e futura?

Pensando a ação cotidiana dos professores, de modo geral se pode ouvi-los e vê-los manifestar-se constantemente sobre a necessidade de que tenham maiores participações em cursos práticos, ou seja, já estão cansados de teoria e que esta teoria não serve para nada no interior da sala de aula. Percebe-se que os professores enxergam a sua prática como "um simples dado que não exige explicação"; (VÁSQUEZ, 2007, p. 80/grifos nosso). Constantemente ouvimos dos professores em processos formativos "Na Universidade a teoria é uma coisa e na sala de aula a prática é outra". Ora, não pode existir maior contradição em tal afirmação pois sabemos que toda a prática efetivada, vivida pelos professores no cotidiano está permeada por alguma teoria. No entanto, a consciência comum, empregada no ato de fazer naturalmente, porque já está cansado de saber pela repetição que acontece todos os dias da mesma forma, faz com que ele acredite que sua prática cotidiana é a-teórica; por isso,

... não sente necessidade de rasgar a cortina de preconceitos, hábitos mentais e lugares comuns, acredita viver - à margem de toda teoria, à 


\section{SEMINÁRIO DE PESQUISA EM CIÊNCIAS HUMANAS - SEPECH \\ Humanidades, Estado e desafios didático-científicos \\ Londrina, 27 a 29 de julho de 2016}

margem de um raciocínio que viria arrancá-lo da necessidade de responder às exigências práticas, imediatas da vida cotidiana (VAZQUEZ, 2007, p. 9).

O cotidiano dos professores está condicionado histórica e socialmente e podese afirmar que o seu modo de pensar e agir bem como a visão que tem da sua prática cotidiana está permeada pelos "valores, pelas ideias, pelas crenças, juízos", (VAZQUES, 2007 p. 9,grifos nosso) acrescentaríamos, preconceitos e toda sorte de aquisições feitas ao longo da vida; nesse sentido, suas práticas metodológicas refletem a consciência que possuem do que fazem e transparece esta mesma consciência imbricada em determinada ideologia muito embora não percebam, ou se percebem, negam qualquer resquício ideológico nas suas ações, acreditam que a prática é autossuficiente e, portanto prescinde da teoria; além disso, acredita que a prática oferece um repertório de soluções, pois no dia a dia, costuma resolver os problemas que aparecem na sala de aula abandonando gradativamente o hábito de refletir sobre o que faz.

Uma questão a ser discutida é a função docente e a concepção de formação que deve ser adotada nos cursos de licenciatura. De um lado, há a defesa de uma concepção de formação centrada no "fazer" enfatizando a formação prática desse profissional e, de outro, há quem defenda uma concepção centrada na "formação teórica" onde é enfatizada, sobretudo, a importância da ampla formação do professor.

É necessário repensar a formação dos professores para que possam enfrentar as novas e diversificadas tarefas que lhes são confiadas na sala de aula e além dela.

\section{ALGUMAS CONSIDERAÇÕES EM RELAÇÃO AO PNEM}

Passamos a apresentar algumas considerações a respeito da experiência da formação de professores no âmbito do Pacto Nacional, a partir das manifestações de professores e orientadores de estudo. Julgamos ser importante perguntar: Seria possível reinventar a escola? Com quais ferramentas, sob quais condições e com quais perspectivas? É nesse contexto a experiência com o Pacto vem a se apresentar como importante e fundamental estratégia para uma transformação, mesmo que acanhada e localizada, de caminhos diversos e diferentes para melhorar as condições de ensino dos jovens estudantes do ensino médio.

Para avaliação das atividades da primeira etapa foi elaborado um questionário semiestruturado com o apoio da ferramenta online e enviado a professores $\mathrm{e}$ orientadores. O questionário tinha por objetivo avaliar a totalidade do trabalho desenvolvido. As questões versavam sobre: dificuldades, metodologia empregada nos cursos, material pedagógico (cadernos), contribuição dos conteúdos, dificuldades em desenvolver as atividades de reflexão, influência das discussões do Pacto no coletivo da escola, a participação dos professores que se envolveram no programa, o trabalho do orientador de estudos, a formação proporcionada pelo Programa Pacto, os Cadernos de Estudo seus conteúdos e escrita. 


\section{SEMINÁRIO DE PESQUISA EM CIÊNCIAS HUMANAS - SEPECH \\ Humanidades, Estado e desafios didático-científicos \\ Londrina, 27 a 29 de julho de 2016}

Considerando os registros dos questionários aplicados ${ }^{1}$ junto a professores e orientadores de estudos podemos elencar algumas avaliações que corroboram com a análise aqui desenvolvida. Os professores do Pacto avançam na perspectiva de compreensão da relação teoria pratica, ou seja da construção da práxis.

$\mathrm{O}$ estudo teórico dos professores permeado com reflexões sobre sua pratica cotidiana realizada de maneira coletiva possibilitou um avanço uma descoberta, a exemplo das seguintes avaliações:

Com este estudo foi possível identificar algumas falhas e tentar buscar melhorar o trabalho pedagógico. Acredito que um fator preponderante é a reflexão que o estudo pode proporcionar, ele direciona o professor a ter um novo olhar para aquele aluno matriculado no Ensino Médio noturno e que enfrenta muitas barreiras para estar ali, buscando melhorar sua condição de vida através do estudo. (Professor 50)

Os professores relataram que foi possível identificar algumas falhas e a necessidade de rever suas práticas. O professor 93 também destaca abaixo:

O estudo tem me obrigado a rever e analisar muitas das minhas ações em sala de aula, no sentido de dar significado ao que estou ensinando e para que estou ensinando determinado conteúdo pensando no sujeito educando como um todo. (Professor n. 93)

Outro professor reconhece os desafios propostos pela mudança

Sim, o homem por sua própria natureza traz em si o desejo da investigação da busca de resolução de problemas, por isto, ele é um ser que transforma a realidade que lhe está trazendo desconforto. Esta etapa do curso começou a despertar em mim desejos de mudanças, embora ela não se dá imediatamente ela vai sendo conquistada gradativamente, e também aceitar os desfio para mudarmos realidade do ensino médio do brasil. (Professor n. 94)

Ampliou meus conhecimentos teóricos, e dessa forma a prática também foi melhor refletida. (Professor, n. 97)

Pode-se perceber pela análise dos depoimentos dos professores que alguma mudança está se realizando. Os professores foram colocados diante de situações conflitivas a partir da inserção nas leituras e momentos de estudo dos Cadernos Temáticos que os têm desafiado a pensar sobre questões com as quais lidam todos os dias e que acabaram por se naturalizar pela frequência com que acontecem na escola; questões como a reprovação, a evasão, as dificuldades de aprendizagem, a indisciplina e tantas outras. Estas se tornaram rotina do funcionamento da escola, e portanto, fazem

\footnotetext{
${ }^{1}$ Devemos esclarecer que de acordo com a organização do Pacto, enquanto professores das IES, nosso contato se deu diretamente com os professores orientadores de estudo, portanto o que registramos foi pela avaliação deles realizado por meio de um questionário aplicado pelo Google docs. Assim para manter a identidade dos participantes eles são denominados em ordem numérica.
} 


\section{SEMINÁRIO DE PESQUISA EM CIÊNCIAS HUMANAS - SEPECH \\ Humanidades, Estado e desafios didático-científicos \\ Londrina, 27 a 29 de julho de 2016}

parte da consciência comum dos professores carecendo e maiores cuidados. Estes acreditam que para elas não há saída e o que é mais grave, acreditam que estão fazendo tudo o que é possível para que os alunos aprendam. Logo, ao se depararem com os dados numéricos sobre a entrada e saída dos alunos do ensino médio no Brasil, apresentados no Caderno de número um e ainda discutirem sobre a condição das juventudes na atualidade, acreditamos que algo de novo surgiu. Isto se deve a nosso ver, ao impacto que tais leituras puderam provocar nos professores. Isto se manifesta por exemplo na afirmação do Professor. 78, quando aponta a necessidade de parar para refletir sobre o seu fazer. Ou seja, "repensar a prática", reconhecer o aluno como sujeito de direito, "rever e analisar as práticas em sala de aula", "despertar o desejo da investigação da busca de resolução de problemas", "ampliar conhecimentos teóricos e refletir sobre a prática".

Observamos ainda que o professor percebeu a ampliação de seu olhar sobre seu trabalho tendo a teoria como elemento de reflexão sobre a sua prática em sala de aula. No conjunto destacamos os seguintes registros:

Proporcionou-me uma visão mais ampla sobre o Ensino Médio, sobre minha profissão como Educador, sobre os alunos, sujeitos no âmbito escolar, de modo geral sobre todo processo educacional. Sobretudo na minha teorização e na minha relação com os alunos. (Professor 51

Após o estudo de uma teoria, a gente adquire novas informações sobre nossa prática pedagógica e sobre o objeto de estudo. Quando vamos elaborar a prática estas novas informações são contempladas, portanto o estudo da primeira etapa foi relevante não só para o enriquecimento de minha prática pedagógica, como para minha aprendizagem. (Professor 80)

Pode parecer pouco, mas, acreditamos é um caminho que aponta para a possibilidade concreta de construir uma práxis libertadora a partir do exercício de compreensão do seu fazer atribuindo-lhe um significado e uma importância até então não reconhecida, até então ofuscada pela consciência comum.

\section{CONSIDERAÇÕES FINAIS}

Esse artigo teve por objetivo apresentar os resultados parciais do Programa Pacto Nacional pelo Fortalecimento do Ensino Médio - Formação continuada de professores e equipes pedagógicas. Analisando os dados coletado por meio de questionários que foram respondidos pelos participantes.

Em termos metodológicos, compreendemos o professor como um sujeito epistêmico, que elabora e produz conhecimentos com base na compreensão da realidade e na perspectiva de transformação da sociedade. A análise dos dados possibilita destacar que é necessário perceber que a "atitude natural cotidiana coexiste com a atitude filosófica surgida historicamente" porque se produz cotidianamente nas ações dos homens- e este cotidiano deve ser o ponto de partida para se chegar a uma "verdadeira concepção filosófica das práxis" (VAZQUEZ, 2007, p.8).

Os resultados preliminares apontam os avanços e fragilidades da formação inicial e continuada do professor do Ensino Médio, no entanto apontam também 


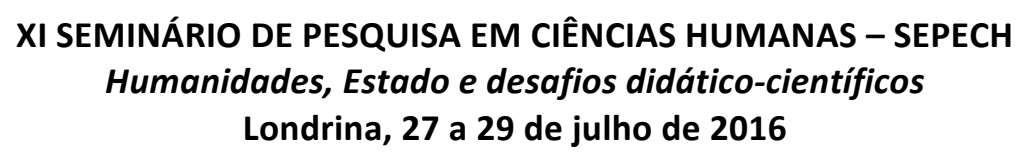

horizontes antes não percebidos, onde é possível sim reinventar a escola e dentro dela e com os alunos construir verdadeiros caminhos para uma visível transformação.

De acordo com GARCIA $(2009$, p.131) a formação inicial, muitas vezes não é suficiente, e nos leva a refletir que o desafio da formação continuada, neste processo, toma dimensões de extrema importância. De acordo com a autora a formação continuada para refletir numa mudança significativa na escola deve ocorrer no chão da escola.

\section{BIBLIOGRAFIA}

BOTTOMORE, Tom. Dicionário do pensamento marxista. Rio de Janeiro: Jorge Zahar. Ed, 2001.

CORRÊA. Vera. As relações sociais na escola e a produção da existência do professor. In FRIGOTO, Gaudêncio; CIAVATTA, Maria, RAMOS, Marise (orgs.). Ensino Médio integrado: concepção e contradições. São Paulo: Cortez, 2005.

GARCIA, S. R. O. A Educação Profissional integrada ao Ensino Médio no Paraná: avanços e desafios. Tese de doutorado. UFPR, Curitiba, 2009.

NETTO, José Paulo. Economia Política: uma introdução crítica - 2ed. - São Paulo: Cortez, 2007.

MINISTÉRIO DA EDUCAÇÃO Secretaria de Educação Básica Diretoria de Apoio à Gestão Educacional. PACTO NACIONAL PELO FORTALECIMENTO DO ENSINO MÉDIO: Documento orientador das ações de formação continuada de professores e coordenadores pedagógicos do Ensino Médio em 2014. Disponível em http://pactoensinomedio.mec.gov.br/images/pdf/documento orientador.pdf. Acesso em 30 de abril de 2016.

VASQUEZ, Adolfo S. Filosofia da Práxis. Bueno Aires: Consejo Latinoamericano de Ciencias Sociales - CLACSO; São Paulo; Expressão Popular, 2007 